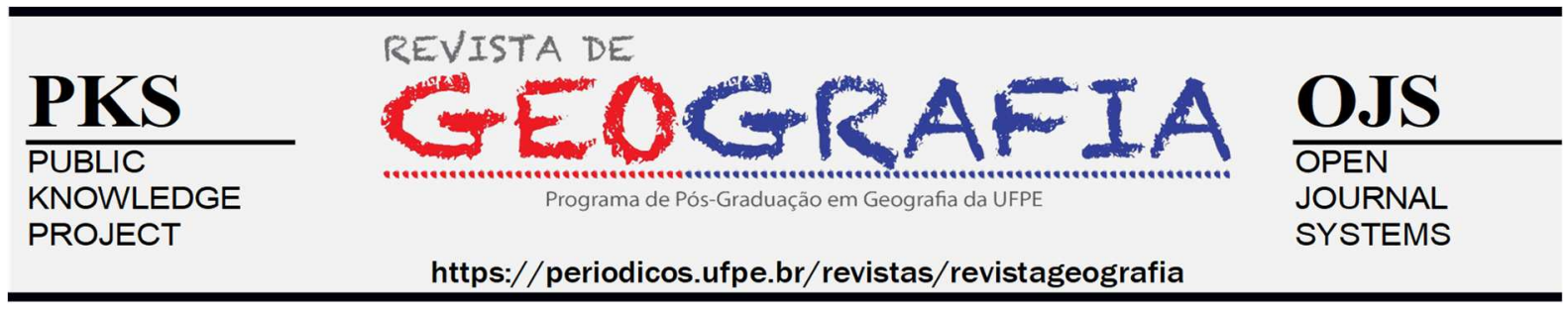

\title{
CRIMINALIDADE E AMBIENTE CONSTRUÍDO: O CASO DO CENTRO HISTÓRICO DE BELÉM (PA)
}

\author{
Marco Aurélio Arbage Lobo ${ }^{1}$, Helena Lúcia Zagury Tourinho², Roberta Dannyele \\ Oliveira Raiol ${ }^{3}$, Sara Melissa Furtado Arnoud ${ }^{4}$
}

${ }^{1}$ Dr. em Desenvolvimento Socioambiental, Professor e Pesquisador da Universidade da Amazônia (UNAMA), Belém/PA; E-mail: lobo2502@gmail.com; https://orcid.org/0000-0002-3366-4992

2 Dra. em Desenvolvimento Urbano, Professora e Pesquisadora da Universidade da Amazônia (UNAMA), Belém/PA; E-mail: helenazt@uol.com.br; https://orcid.org/0000-0001-7588-1680

${ }^{3}$ M.Sc. em Zoologia, Professora e Pesquisadora da Universidade da Amazônia (UNAMA), Belém/PA; E-mail: raiol06@gmail.com; https://orcid.org/0000-0002-7552-7988

4 Arquiteta e Urbanista; Universidade da Amazônia (UNAMA); E-mail: smarnoud.arq@gmail.com; https://orcid.org/0000-0002-5061-2641

Artigo recebido em 29/12/2020 e aceito em 03/03/2021

\begin{abstract}
RESUMO
Vários estudos têm investigado a distribuição espacial das ocorrências de crimes nas cidades e a influência de fatores do ambiente construído nessa distribuição. Diante da elevada quantidade de crimes contra o patrimônio (furtos e roubos) no Centro Histórico de Belém, o trabalho procura identificar o padrão da distribuição geográfica desses eventos e identificar aspectos espaciais que neles interferem. Para isso: constrói sistema de informações geográficas usando dados coletados em boletins de ocorrências policiais; analisa mapas de calor indicativos das áreas de concentração de crimes; e relaciona essas áreas com características do ambiente construído. A análise dos resultados indicou que a maioria desses delitos ocorre principalmente onde há concentração de lojas e estabelecimentos de serviços, em vias largas e nas proximidades de praças. Também conclui que a literatura sobre o tema apresenta lacunas para explicar as peculiaridades dos centros comerciais de grandes cidades.
\end{abstract}

Palavras-chave: criminalidade urbana; ambiente construído; centro comercial de cidades.

\section{CRIMINALITY AND BUILT-IN ENVIRONMENT: THE CASE OF THE HISTORICAL CENTER OF BELÉM (PA)}

\section{ABSTRACT}

Several studies have investigated the spatial distribution of crime occurrences in cities and the influence of environmental built factors on this distribution. In view of the high number of crimes against property (theft and robbery) in the Historic Center of Belem, the work aims to identify the pattern of the geographic distribution of these events and to identify spatial aspects that interfere with them. For that: it builds geographic information system using data collected in police reports; analyzes heat maps indicative of crime concentration areas; and it relates these areas with characteristics of the built environment. The analysis of the results indicated that most of these crimes occur mainly where there is 
a concentration of economic establishments, on wide roads and close to squares. It also concludes that the literature on the subject has gaps to explain the peculiarities of downtown areas in large cities.

Keywords: urban crime; built environment; downtown area.

\title{
CRIMINALIDAD Y ENTORNO CONSTRUIDO: EL CASO DEL CENTRO HISTÓRICO DE BELÉM (PA)
}

\begin{abstract}
RESUMEN
Varios estudios han investigado la distribución espacial de los casos de delitos en las ciudades y la influencia de los factores ambientales construidos en esta distribución. Ante el elevado número de delitos contra la propiedad (hurto y robo) en el Centro Histórico de Belém, el trabajo busca identificar el patrón de distribución geográfica de estos hechos e identificar aspectos espaciales que los interfieren. Para eso: construye un sistema de información geográfica utilizando los datos recopilados en los informes policiales; analiza mapas de calor indicativos de áreas de concentración de delitos; y relaciona estas áreas con características del entorno construido. El análisis de los resultados indicó que la mayoría de estos delitos ocurren principalmente donde hay una concentración de tiendas y establecimientos de servicios, en vías anchas y cercanas a plazas. También concluye que la literatura sobre el tema tiene lagunas para explicar las peculiaridades de los centros comerciales en las grandes ciudades.
\end{abstract}

Palabras clave: crimen urbano; entorno construído; centro comercial de las ciudades.

\section{INTRODUÇÃO}

Em 2017 o Brasil alcançou a marca histórica de 65.602 homicídios e uma taxa de 31,6 mortes registradas a cada 100 mil habitantes, segundo o Instituto de Pesquisas Econômicas Aplicadas (IPEA) e o Fórum Brasileiro de Segurança Pública (IPEA; FBSP, 2019). Esta taxa de homicídios representa 30 vezes observada no continente europeu, por exemplo. Na América do Sul, o país está apenas atrás da Venezuela, que apresenta uma taxa igual a 56,8 homicídios, de acordo com os estudos do Escritório das Nações Unidas sobre Drogas e Crime (UNITED NATIONS OFFICE ON DRUGS AND CRIME, 2019). Para efeito de comparação, as duas menores taxas do continente são Chile (3,5 homicídios por 100 mil habitantes) e Argentina $(5,1)$.

O mesmo estudo brasileiro revela ainda uma heterogeneidade na distribuição desses homicídios pelo país, onde as regiões Nordeste e Norte apresentaram as maiores taxas, respectivamente iguais a 47,1 e 45,7 a cada100 mil/habitantes, onde ainda os estados do Rio Grande do Norte (62,8 mortes por $100 \mathrm{mil} / \mathrm{hab}$.) e Acre (62,2 mortes por $100 \mathrm{mil} / \mathrm{hab}$.) apresentaram os maiores índices. Ressalte-se também que a criminalidade nas cidades vem crescendo, independente desta ser uma metrópole ou cidade de pequeno porte (WAISELFSZ, 2015; ENDLICH; CARNEVALLI FERNANDES, 2014). 
Ainda para o IPEA e o Fórum Brasileiro de Segurança Pública (2019), tais disparidades e o aumento observado nas taxas de homicídios em 2017 estão diretamente ligados às questões sociais como desigualdade de gênero e racial e à morte de jovens, já que as maiores taxas são observadas no público entre 15 e 29 anos. O estudo observa, ainda, o aumento de homicídios em segmentos sociais específicos - como população negra, LGBTI e mulheres. Para as regiões Nordeste e Norte, tais aumentos ainda podem estar relacionados, a guerra entre facções e aumento do narcotráfico comandados por grupos aliados à grandes facções como Primeiro Comando da Capital (PCC) e o Comando Vermelho (CV) (MANSO; DIAS, 2018).

Considerando a região Norte, o estado do Pará, em 2017, ficou em $2^{\circ}$ lugar com uma taxa de homicídios igual a 54,7 de mortes a cada 100 mil habitantes, taxa essa que saltou para 74,6 homicídios a cada 100 mil habitantes quando analisado o munícipio e capital do estado Belém, seguido pelos municípios de Altamira, Ananindeua, Marabá e Marituba, todos no ranking dos vinte mais violentos do país (IPEA; FBSP, 2019).

Dentro da capital paraense, uma das áreas com maior incidência de ocorrências criminais, principalmente crimes contra o patrimônio como furtos e roubos, é a grande aglomeração de estabelecimentos de comércio e serviços existente no Centro Histórico de Belém (CHB).

O CHB é composto pelos bairros da Campina e parte da Cidade Velha e área portuária do Reduto e Umarizal conforme a Lei 7.709/1994 (BELÉM, 2004). Dentre esses bairros destaca-se o da Campina, que apresenta forte característica comercial, preservada desde seu surgimento à atualidade, razão pela qual é conhecido pelos moradores belenenses como "Bairro do Comércio" - mesmo que haja significativo número de moradias na área.

A relação entre o espaço construído e criminalidade vem sendo discutida em diversas pesquisas sobre as cidades contemporâneas, tendo sua origem na década de 1960 com os trabalhos de Jane Jacobs e Oscar Newman, principalmente com a crítica ao urbanismo modernista.

De acordo com as várias teorias que trabalham a relação entre espaço construído e criminalidade, a configuração física do espaço edificado, bem como o tipo e a distribuição das atividades - uso do solo - nele presentes, contribui para aumentar ou diminuir a sensação de medo e a ocorrência de eventos criminais.

Devido à importância econômica, social e cultural do Centro Histórico de Belém e ao elevado número de eventos criminais contra o patrimônio que ocorrem nessa área (furtos e 
roubos), este trabalho teve por objetivo principal investigar a quantidade e a forma como se dá a distribuição espacial desses eventos, de forma a responder às seguintes perguntas: como os furtos e roubos estão distribuídos territorialmente no CHB? Estão dispersos por toda a área de estudo ou formam concentrações de ocorrências (hotspots)? Que aspecto(s) da organização espacial do CHB mais interfere(m) na ocorrência desses eventos criminais?

O objetivo deste trabalho é, então, verificar se organização funcional e a configuração física do espaço construído do Centro Histórico de Belém têm relação com a distribuição espacial da ocorrência de roubos e furtos e, em caso positivo, que fatores são esses e como eles interferem na ocorrência desses delitos.

O artigo está estruturado em cinco partes. A primeira é esta introdução. A segunda apresenta as principais teorias que discutem a relação entre espaço construído e ocorrência de crimes. A terceira detalha os procedimentos metodológicos adotados. A quarta discute os resultados obtidos. A quinta expõe as considerações finais do trabalho.

\section{QUADRO TEÓRICO}

Várias foram as teorias criadas para explicar a relação do espaço construído e a criminalidade. Dentre essas pode-se citar a teoria CPTED (Crime Prevention Through Environmental Design), ou Prevenção de Crimes por Meio do Desenho Ambiental. A origem dessa teoria está nas críticas feitas às cidades modernistas, aos fundamentos do planejamento e às políticas de renovação urbana vigentes nos anos 1950.

Jacobs (2011) questiona a setorização rígida das atividades urbanas (habitação, trabalho, diversão e circulação) defendida pela Carta de Atenas de 1933, e sustenta que a diversidade de usos do solo é o único meio capaz de garantir a vitalidade urbana e a segurança nos espaços públicos. Para essa autora, a presença intensiva de usuários no espaço público contribui para aumentar a quantidade de pessoas vigilantes e torna a rua mais interessante para quem a observa de dentro dos edifícios e segura para quem nela circula (JACOBS, 2011). Além disso, com mais pessoas, durante uma eventual fuga de alguém que praticou um delito, aumentam as possibilidades de que essa pessoa seja perseguida e capturada (SOARES; SABOYA, 2019), o que auxiliaria na diminuição de crimes.

É importante observar que a crítica de Jacobs (2011) foi feita dentro de um contexto bem específico: os impactos negativos das intervenções urbanas do movimento modernista nas grandes cidades norte-americanas. Por isso, é preciso avaliar até que ponto as observações da 
autora se aplicam ao contexto do Centro Histórico de Belém, caracterizado por ser uma área que tem elevada ocorrência de furtos e roubos ao longo de todo o dia com maiores ocorrências nos horários de grande movimento. De todo modo, a ideia da vitalidade do espaço público, ao criar mecanismos naturais de vigilância, é de grande importância para a segurança pública.

Outro conceito importante na evolução das teorias da relação entre espaço construído e criminalidade é o de "espaço defensável”, de Newman (1996), cuja obra original é de 1972. $\mathrm{O}$ autor se baseia na ideia de que os seres humanos têm um instinto nato de territorialidade, pelo qual tendem a defender o território que consideram seu. Nesse sentido, alguns tipos de organização residencial facilitam ou dificultam a sensação de pertencimento a um lugar, algo que o autor considera de grande importância para que os moradores desenvolvam atitudes vigilantes em relação à segurança do lugar.

Oscar Newman argumenta que algumas tipologias habitacionais têm maior probabilidade de ser objeto de ocorrências criminais do que outras. Isso porque tais tipologias não conseguem desenvolver, no morador, a sensação de pertencimento ao local onde mora, o que reduz as atitudes de vigilância. A partir desse pressuposto, Newman classificou os tipos de moradias em três grupos: residências unifamiliares; residências multifamiliares de baixa verticalidade que são edifícios de até três pavimentos, chamados walk-ups, por dispensar elevadores; e residências multifamiliares de alta verticalidade (high-rises ou arranha-céus).

$\mathrm{O}$ autor explica que, nas quadras modernistas, existe uma grande concentração de habitações verticalizadas, sendo o térreo compartilhado por todos, o que dificulta o surgimento de um sentimento de propriedade e responsabilidade pelo espaço partilhado. Outra observação de Newman é que há uma correlação entre a ocorrência de crimes, famílias de baixa renda e projetos de habitação social. Sendo assim, para ele, as variáveis mais influentes são a situação socioeconômica e o tamanho dos projetos de habitação destinados a essas pessoas. O trabalho cita o caso do premiado conjunto habitacional modernista Pruitt-Igo, em Saint Louis (Missouri). Construído na década de 1950, o conjunto sofreu um rápido processo de degradação física e de crescimento da criminalidade no seu interior. Por isso, foi demolido em 1972.

Ainda para Newman, os infratores medem suas decisões baseados numa relação de custo vs. benefício, ou seja, estes selecionam um cenário onde os riscos são minimizados e as recompensas maximizadas. Assim, os espaços que facilitem a observação, a vigilância, o controle de acesso e a redução de rotas de fuga desestimulam a ação dos delinquentes. 
Para o autor, a solução para a redução das taxas de criminalidade está na criação de "minivizinhanças". As minivizinhanças têm por objetivo proporcionar espaços onde as pessoas possam se reconhecer e interagir, reconhecer o lugar onde moram e desenvolver a sensação de pertencimento, com o aumento da vigilância natural, o que leva ao controle do acesso a esses espaços por parte pessoas estranhas. As mesmas seriam criadas seguindo os princípios a seguir: (1) limitação da comunidade habitante de cada minivizinhança para a criação de uma identidade compartilhada; (2) uso de cul-de-sacs para desencorajar o tráfego de veículos de não residentes; (3) acesso por vias arteriais que facilitem a entrada de veículos de emergência e visitantes e mas não incentivem o fluxo de veículos externos; (4) habitações com características semelhantes; e (5) participação da população interessada na delimitação das minivizinhanças.

Outras teorias mais atuais também consideram que a presença de um número muito grande de indivíduos nas ruas pode ajudar a encobrir ocorrências como furtos e pequenos roubos (COZENS; SAVILLE; HILLIER, 2005).

Bill Hillier (2007), que desenvolveu o conceito de Sintaxe Espacial, antes de confrontar os aspectos físicos relacionados à segurança, preocupa-se em estudar as relações de sociabilidade proporcionadas pelos espaços construídos. Para essa análise, a prioridade são os locais de encontro, como os espaços públicos, e a principal variável é a integração, ou seja, “[...] o grau de acessibilidade por pedestres e veículos e a conexão do lugar com outras áreas da cidade. A integração condiciona o movimento de pessoas e atividades em uma região" (SOUZA; COMPANS, 2009, p. 17).

A teoria de Hillier tem fundamento na questão de planejar um espaço onde os fluxos e movimentos maximizem os encontros e limitem a segregação. Por defender que a presença de estranhos é importante na manutenção da segurança nos espaços públicos, Hillier não encoraja o uso do conceito de minivizinhanças de Newman.

O conceito de "espaço defensável" foi formulado partir do estudo de áreas residenciais, o que traz limitações para que suas conclusões e recomendações para locais como o CHB, que têm uma forte característica comercial. Ainda assim, duas ideias principais dessa teoria podem ser utilizadas: (1) a importância da redução das rotas de fuga; e (2) a necessidade da criação de um sentimento de comunidade, neste caso, especialmente nas áreas do CHB onde o uso é predominantemente comercial. A criação de minivizinhanças até poderia ser parcialmente viável em algumas áreas habitacionais do CHB, mas as críticas de Hillier a esse conceito podem ser consideradas pertinentes. 
A teoria CPTED surgiu em 1971 com Clarence Ray Jeffery e constitui uma abordagem multidisciplinar sobre o comportamento criminoso. Esse autor também defende a ideia de que a forma como se estrutura o espaço construído influencia a decisão do delinquente de praticar ou não um delito, especialmente a possibilidade de fuga do local.

De acordo com Cozens (2005), diversos autores teceram críticas à formulação original da CPTED, argumentando que, por estar muito direcionada para os aspectos físicos do ambiente, trata de forma simplista a relação entre criminalidade e territorialidade, além de não considerar características e motivação dos delinquentes (SOUZA; COMPANS, 2009).

O que ficou conhecido como CPTED de $1^{\text {a }}$ Geração (teorias de Newman e Jeffery) foi aprimorado por pesquisadores, profissionais e decisores políticos. Como resultado, foi criada uma abordagem mais consistente, que ficou conhecida como CPTED de $2^{\mathrm{a}}$ geração. $\mathrm{O}$ refinamento em questão vai além do mero design físico e inclui fatores sociais.

O CPTED de segunda geração utiliza avaliação de risco e perfil socioeconômico e demográfico, além de participação ativa da comunidade na discussão e na solução dos problemas. De forma geral, as teorias baseadas em CPTED adotam estratégias comuns que pretendem influenciar as decisões dos infratores: vigilância natural, reforço territorial, controle de acesso natural e manutenção qualidade física do espaço construído.

A qualidade da condição física do espaço construído, que pode afetar a percepção dos usuários a respeito do controle social, induz à percepção de que há ambientes mais protegidos ou mais vulneráveis. Este é um ponto basilar da teoria das Janelas Quebradas, pela qual espaços deteriorados e com sinais de negligência estão relacionados com a sensação de insegurança e a falta de controle social e tornam as áreas cada vez menos utilizadas e mais perigosas (WILSON; KELLING, 1982). Esses processos compõem um círculo vicioso, visto que a deterioração, que é proveniente da falta de controle e da apropriação do espaço pelos usuários, afasta as pessoas dos espaços levando ao abandono ainda maior.

Quando existe a manutenção rotineira do espaço construído, existe a promoção de uma imagem positiva do ambiente, o que indica que o espaço é território protegido e incentiva o uso devido, transmitindo sinais positivos a todos os usuários (COZENS; SAVILLE; HILLIER, 2005). A manutenção adequada envia uma mensagem de orgulho, propriedade, proteção e preocupação.

A disponibilidade de rotas de fuga para o agressor é outro fator importante na forma como o espaço construído influencia a criminalidade. A rota de fuga constitui um elemento de 
importância crucial para a viabilizar da prática do delito, pois proporciona esconderijo seguro tanto para sair do campo de visão após o crime como para surpreender um possível alvo. De acordo com o tipo de crime e de alvo, pode ser necessária uma fuga em alta velocidade, o que exige uma via que permita a saída rápida de um veículo, ou uma fuga sem despertar atenção como misturar-se, normalmente, ao fluxo de pessoas, por exemplo.

A rota de fuga também está relacionada ao conceito de permeabilidade do espaço ao movimento de pedestres e de veículos. De acordo com Cozens, Saville e Hillier (2005), a maior permeabilidade pode aumentar a movimentação de pessoas em um local, mas também pode facilitar rotas de fuga e aumentar o número de alvos para o agressor, tornando-se algo que merece um estudo mais aprofundado. Dessa forma, a possibilidade da existência de rotas de fuga para o agressor é um aspecto relevante a ser analisado na organização espacial do CHB.

Soares e Saboya (2019), baseando-se nas teorias anteriormente expostas, propõem um modelo que integra o ambiente físico e a ocorrência de crimes em uma estrutura lógica, de forma a possibilitar explorar as conexões causais e fatores envolvidos em diversos tipos de crimes. O modelo apresenta uma rede que integra a lógica do crime e os fatores para que isto ocorra, considerando três elementos decisivos que precisam se encontrar no espaço e no tempo: um agressor motivado, um alvo adequado e a falta de guardião capaz. Além disso, os autores destacam a importância dos macropadrões cotidianos de deslocamento casa-trabalho, que são influenciados pela configuração da malha urbana e têm papel fundamental na determinação dos locais onde se encontram os agressores e suas potenciais vítimas.

Assim, para a ocorrência de crimes são necessários o acesso a um alvo adequado e a consciência, por parte do agressor, de que ele existe e é possível de ser alcançado. Segundo essa teoria, esses elementos são definidos pelo modo como o espaço está organizado, assim como a presença ou não de guardiões capazes de evitar o delito. O modo como diferentes ambientes se relacionam e a forma como os lugares da cidade se dispõem no tecido urbano são, portanto, mediadores dos fatores de ocorrências criminais (SOARES; SABOYA, 2019).

Souza e Compans (2009) destacam que a teoria CPTED, no Brasil, fundamenta um amplo conjunto de novas abordagens sobre a segurança pública, denominada de "segurança cidadã", pela qual a segurança pública deixa de ser uma responsabilidade exclusiva de ações repressivas da autoridade policial e incorpora também medidas preventivas - dentre elas as ações de desenho urbano voltadas para tornar o espaço público mais seguro - e o apoio da comunidade. 
Diante do exposto, passa-se a apresentar o estudo do caso do CHB, buscando-se articular as evidências empíricas identificadas nesta pesquisa com os aspectos teóricos citados nesta seção.

\section{MATERIAIS E MÉTODOS}

Para o presente artigo foram utilizados três procedimentos de pesquisa. O primeiro consistiu nos levantamentos bibliográficos e documentais destinados a subsidiar a construção do quadro teórico, bem como, a elaboração do histórico e a análise dos aspectos legais utilizados para a caracterização da organização físico-territorial da área de estudo.

O segundo foi a sistematização e análise de informações estatísticas a partir de informações presentes no registro dos eventos criminais (boletins de ocorrência - BOs) que ocorreram durante o ano de 2017. As informações contidas nos boletins de ocorrência, feitos pelas vítimas, foram disponibilizados aos autores pela Polícia Civil do Pará por meio de uma planilha eletrônica no formato "xls" (PARÁ, 2019). Tais BOs contêm o tipo do crime (furto, homicídio doloso, lesão corporal e roubo), a data, o horário e o endereço do local onde ocorreu, dentre outras informações.

O terceiro procedimento foi a sistematização e análise das informações geográficas. Os endereços onde ocorreram os eventos criminais, disponibilizados nos BOs, foram convertidos em coordenadas geográficas com o uso do site GoogleMaps e inseridas na planilha. O próximo passo foi converter o arquivo da planilha eletrônica em mapa de pontos georreferenciados no formato "shp" com uso do programa QGIS. Como resultado, teve-se a distribuição espacial dos pontos que representam os eventos criminais.

Considerou-se na análise espacial apenas os furtos e os roubos, enquanto os dados de homicídios e lesões corporais tiveram apenas tratamento estatístico, em razão de terem ocorrido em número muito menor do que os furtos e roubos. Para investigar a distribuição espacial das ocorrências de furtos e roubos, gerou-se um mapa de calor (interpolação Kernel) para cada tipo de delito no programa CrimeStat 4, que resultou arquivos no formato "shp". Os arquivos foram, então, carregados no programa QGIS, o que permitiu visualizar as diversas intensidades de concentração de pontos na área do CHB, bem como os hotspots, áreas em formato de elipse onde estão as maiores concentrações de pontos. Finalmente, realizou-se um levantamento fotográfico nos locais dos hotspots mais intensos. 
Os parâmetros usados para gerar os mapas de calor e de hotspots estão apresentados no Quadro 1.

Quadro 1 - Parâmetros usados nos mapas de calor e de hotspots
\begin{tabular}{|l|c|}
\hline \multicolumn{1}{|c|}{ Parâmetro } & Tipo / Valor \\
\hline Método de interpolação & Normal \\
\hline Largura de banda & Adaptativo \\
\hline Tamanho mínimo da amostra & 50 \\
\hline Intervalo (m) & 100 \\
\hline Unidade de área: pontos por & Metro quadrado \\
\hline Unidade de saída & Densidade absoluta \\
\hline Tipo de análise hotspot & spatial clustering \\
\hline Raio de busca & Distância fixa, 100m \\
\hline $\begin{array}{l}\mathrm{N}^{\circ} \text { mínimo de pontos por } \\
\text { agrupamento }\end{array}$ & 50 \\
\hline Unidade de distância de saída & Metro \\
\hline $\mathrm{N}^{\mathbf{o}}$ de desvios padrões das elipses & 1 \\
\hline \multicolumn{1}{|c|}{ Fonte: Autores } \\
\hline
\end{tabular}

Os resultados desta pesquisa foram comparados com os que foram obtidos por Lobo em Guimarães (2013), que utilizaram dados do período de janeiro de 2007 a outubro de 2008.

\section{RESULTADOS E DISCUSSÃO}

Local de origem da ocupação da cidade de Belém - iniciada no século XVII na confluência da Baía do Guajará com o Rio Guamá (Figura 1) - o CHB é composto pelo bairro da Campina e parte do bairro da Cidade Velha. Possui áreas de traçados retilíneos ora regulares, ora mais espontâneos (principalmente no bairro Cidade Velha). Na Cidade Velha, as vias são estreitas asfálticas ou de paralelepípedo, com calçadas estreitas de pedra de lioz, pedra portuguesa ou concreto, possuindo apenas uma faixa de circulação veicular, ladeadas por edificações alinhadas aos limites dos lotes. Na Campina, por seu turno, já se encontram algumas vias mais largas, onde circulam carros, ônibus, caminhões usados para abastecer o comércio local e demais veículos automotores. 


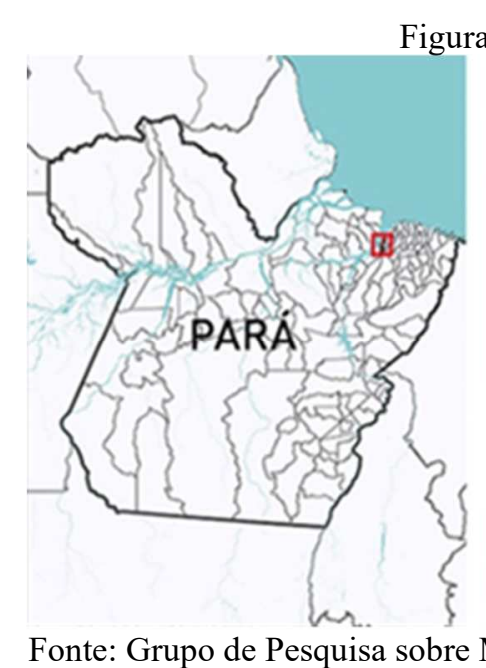

Figura 1 - Localização do Centro Histórico de Belém CHB
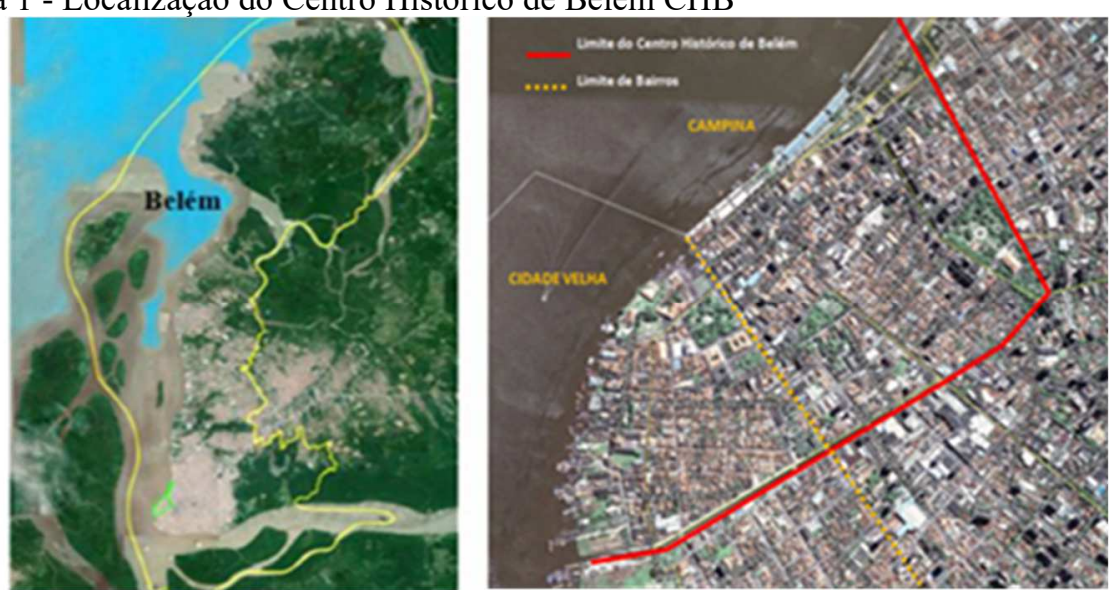

- UNAMA).

A distribuição espacial dos usos do solo se explica pela própria evolução histórica do CHB: as atividades de comércio e serviços estão localizadas mais próximas da orla (Figura 2a), onde historicamente houve um intenso movimento de comércio local, nacional e internacional, enquanto os domicílios ficam na parte mais continental (Figura 2b).

Parte significativa do patrimônio imobiliário edificado encontra-se mal preservada, apresentando forte descaracterização por reformas e usos irregulares, além de haver muitos imóveis abandonados. Nas áreas de grande concentração comercial (Figura 2a), o uso indiscriminado de engenhos publicitários e a intensa e desordenada ocupação de vias públicas por camelôs completam o quadro de descaracterização e degradação do local. 
Figura 2 -Distribuição dos lotes com usos de solo econômicos (a) e habitacionais (b) no CHB, 2013
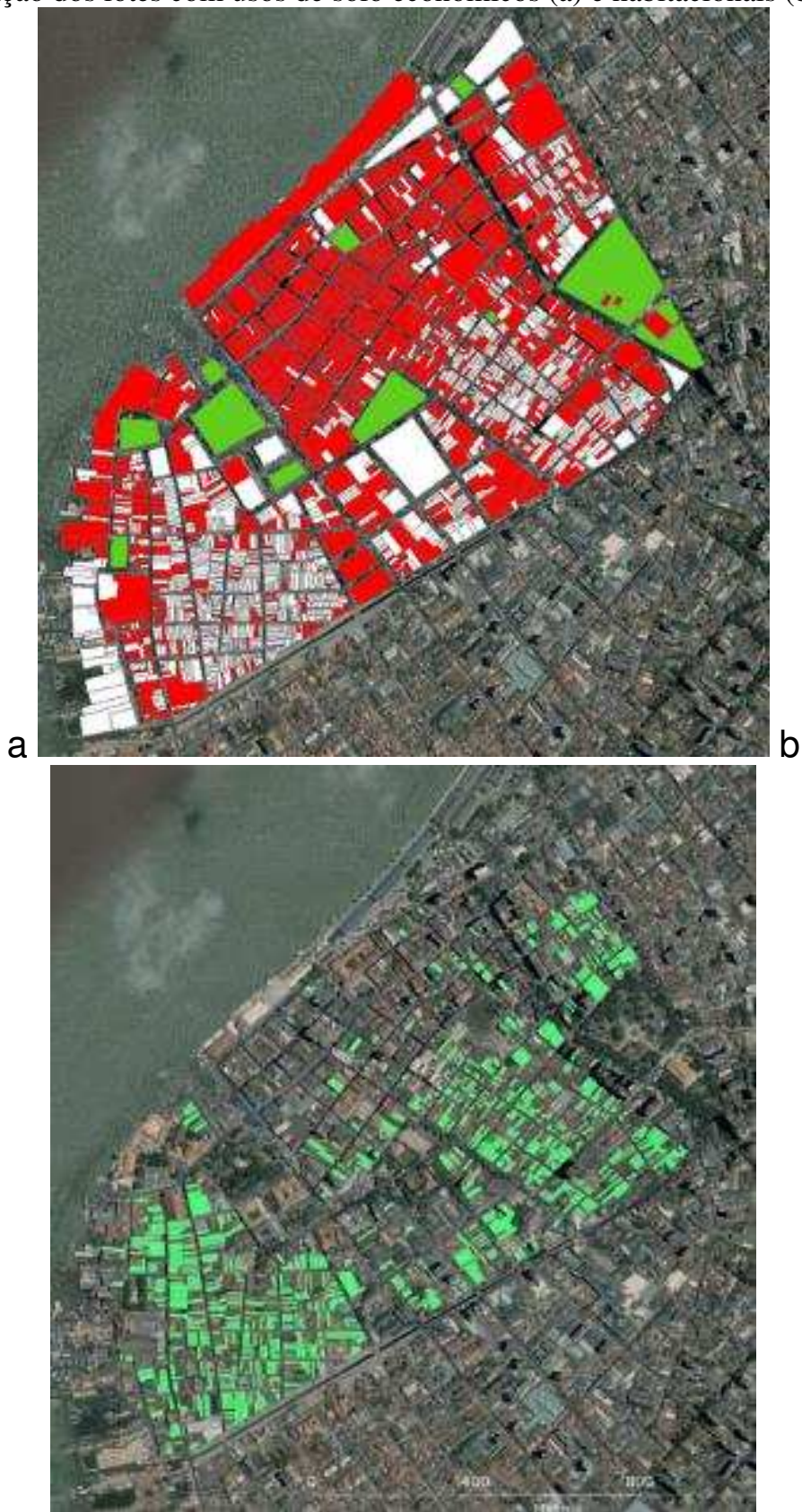

Grupo de Pesquisa sobre Mercado Imobiliário no Centro Histórico de Belém (Universidade da Amazônia UNAMA).

A maioria dos imóveis e espaços públicos deteriorados ou subutilizados se encontra nas aglomerações de comércio e serviços. Nas áreas de predominância de uso residencial, é menor a ocorrência de edificações degradadas.

Majoritariamente, as famílias que ocupam o CHB são de classe média. Prevalecem os setores censitários que apresentam menos de $10 \%$ de domicílios com renda mensal per capita 
de 1/8 de SM ou menos, e somente dois setores censitários (27 e 40) possuíam percentual de famílias pobres situado entre $15 \%$ a $20 \%$ do total.

De acordo com os dados fornecidos pela Polícia Civil do Pará, o total de ocorrências de furtos registrados em BOs no CHB, no ano de 2017, foi de 3.728 casos, enquanto o de roubos totalizou 2.918 ocorrências. Na mesma área, as ocorrências de lesão corporal somaram 209 casos e as de homicídios, 21 registros. Comparando as médias mensais do ano de 2017 (217 furtos e 243 roubos) com as observadas no janeiro de 2007 a outubro de 2008 (22 meses) por Lobo e Guimarães (2013), ou seja, 66 furtos e de 61 roubos, percebe-se que houve um expressivo aumento das duas modalidades de delito. A média mensal de eventos de lesão corporal manteve-se estável (18, contra 17 do ano de 2017, contra 18 no período anterior); mas a média mensal de homicídios cresceu substancialmente: de 0,18 para 1,75.

Quando se compara os principais horários de ocorrência dos delitos, é possível observar que os eventos criminais analisados não apresentaram mudanças importantes nos dois momentos estudados. Furtos acontecem, com maior incidência entre $10 \mathrm{~h}$ e $12 \mathrm{~h}$, e seguem diminuindo até às $24 \mathrm{~h}$ (Figura 3). Os crimes de roubo são mínimos na madrugada e crescem gradativamente durante o dia, atingindo o período de maior incidência entre $18 \mathrm{~h}$ e 20h, horário em que muitas pessoas estão nas ruas para voltar para casa, e que o menor nível de luminosidade facilita o trabalho do agressor. A partir desse horário, as ocorrências diminuem.

Figura 3- Número de delitos por faixa de horário no CHB, 2017

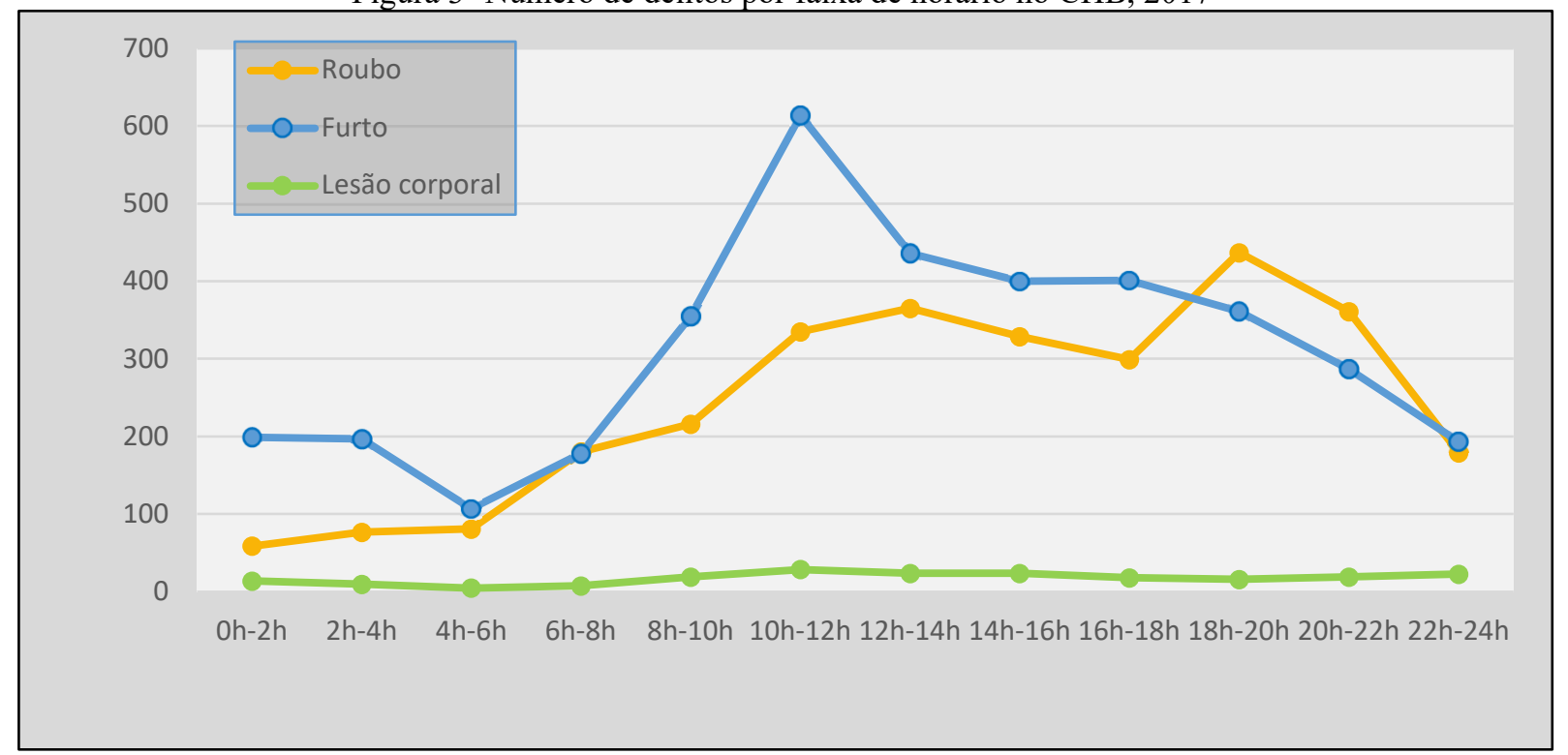

Fonte: Autores, com base em dados obtidos em Pará (2019). 
Ao se comparar com os dados de 2017 com os apresentados no estudo de Lobo e Guimarães (2013), verifica-se que houve poucas mudanças nesse padrão (Figura 4). Corroborase, assim, a importância dos macropadrões de deslocamentos cotidianos casa-trabalho mencionados por Soares e Saboya (2019) como fator que favorece a incidência de crimes.

Figura 4 - Número de delitos por faixa de horário no CHB, 2013

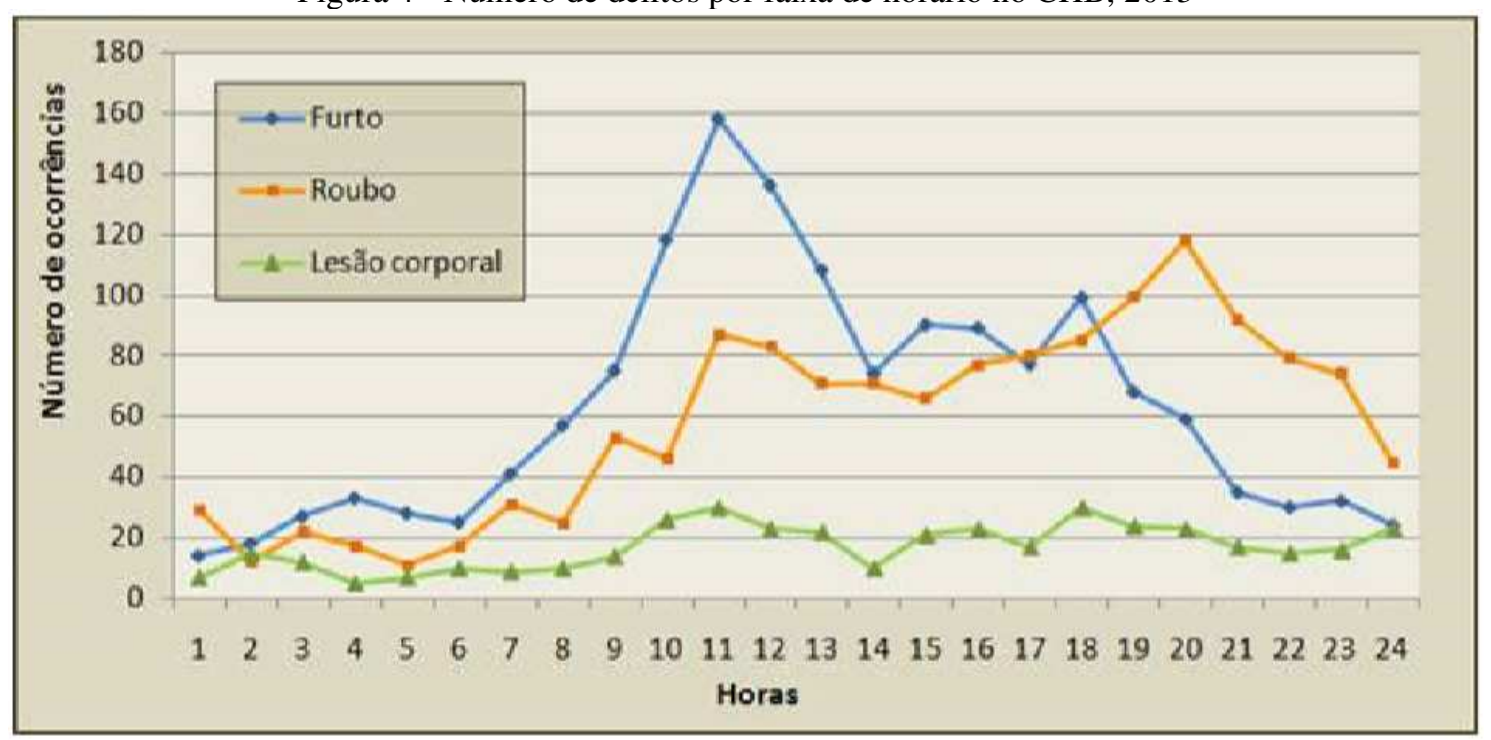

Fonte: Lobo e Guimarães (2013).

Para os crimes de lesão corporal, o período de maior incidência é o mesmo daquele notado para os furtos, ou seja, entre $10 \mathrm{~h}$ e $12 \mathrm{~h}$. Os homicídios tiveram maior incidência entre 4h e 6h. Essa distribuição é muito similar à encontrada por Lobo e Guimarães (2013), sendo diferentes apenas na média de delitos, visto que o número de ocorrências de 2017 é muito maior em comparação ao período janeiro de 2007 a outubro de 2008.

Quanto à distribuição espacial dos furtos e roubos no $\mathrm{CHB}$, principal objeto de estudo deste trabalho, observa-se que os furtos (Figura 5) se concentram em alguns locais, sobretudo nas vias mais largas, corredores de transporte coletivos, onde há concentração comércio e serviços e intenso fluxo de pedestres (Figura 2a).

Daí se conclui que a concentração de potenciais alvos (consumidores e pessoas que trabalham no local) parece ser o motivo principal do padrão de distribuição espacial desse delito. Assim sendo, o conceito de vigilância natural, de grande relevância nas abordagens de Jane Jacobs, Oscar Newman, Bill Hillier, dentre outros autores que investigam a relação entre espaço construído e criminalidade, pouco ajuda na compreensão da distribuição espacial dos eventos criminais em lugares onde há concentração de atividades e grande número de pessoas. 
Figura 5 - Distribuição espacial dos furtos no CHB, 2017

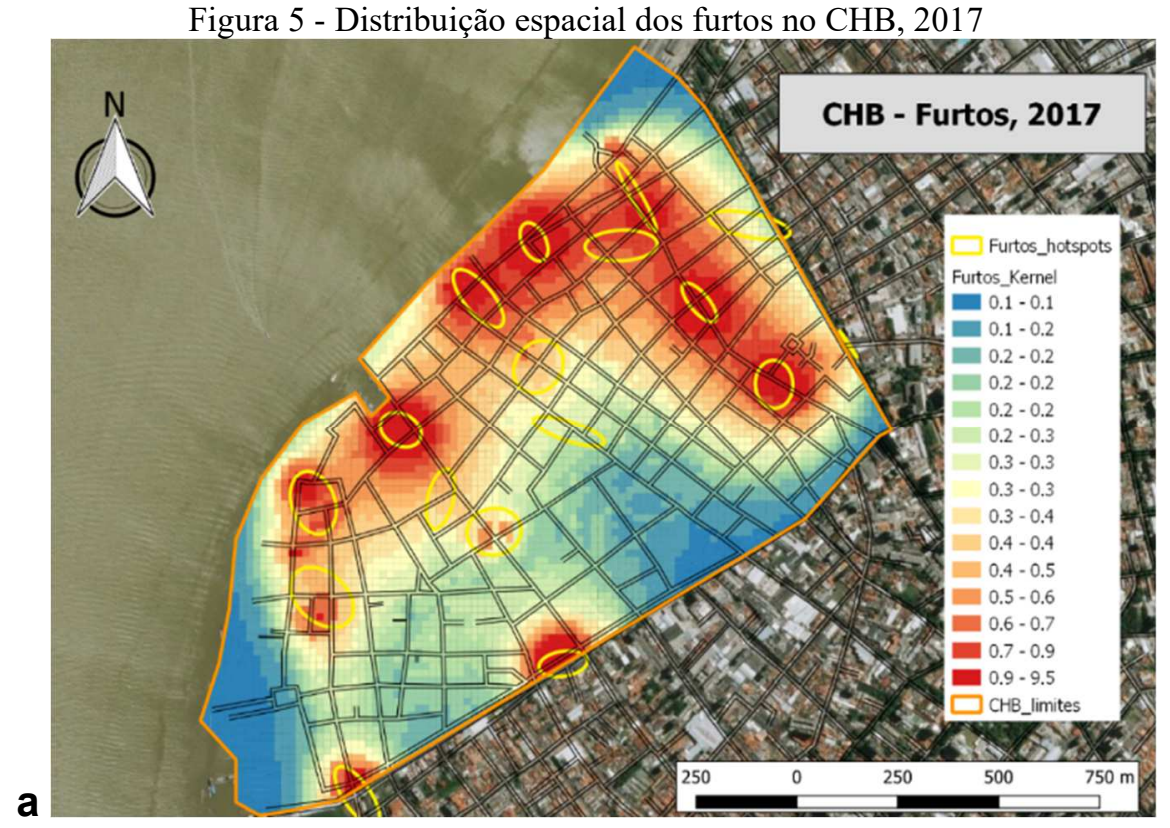

Fonte: Autores, com base em dados obtidos em Pará (2019).

Nesse contexto, parece ser mais pertinente a observação de Cozens, Saville e Hillier (2005) de que uma grande concentração de pessoas nas ruas pode aumentar o número de alvos potenciais e criar obstáculos visuais para que o praticante do crime seja percebido. No caso específico do CHB, o grande número de barracas de camelôs e de vendedores ambulantes também contribui nesse sentido.

Detalhando mais a análise, vê-se que as vias com maior número de hotspots relacionados ao furto (p. ex. Av. Presidente Vargas, Av. Portugal e Av. Boulevard Castilho França), são praticamente as mesmas encontradas por Lobo e Guimarães (2013) (Figura 6).

Portanto, se as manchas mais intensas do mapa de calor estão em várias ruas do centro comercial (todas bem movimentadas), a grande maioria dos hotspots se concentra nessas três vias. Também é interessante registrar que vários hotspots se encontram nas imediações de praças. 
Figura 6 - Distribuição espacial dos furtos no CHB, jan. 2007- out. 2008

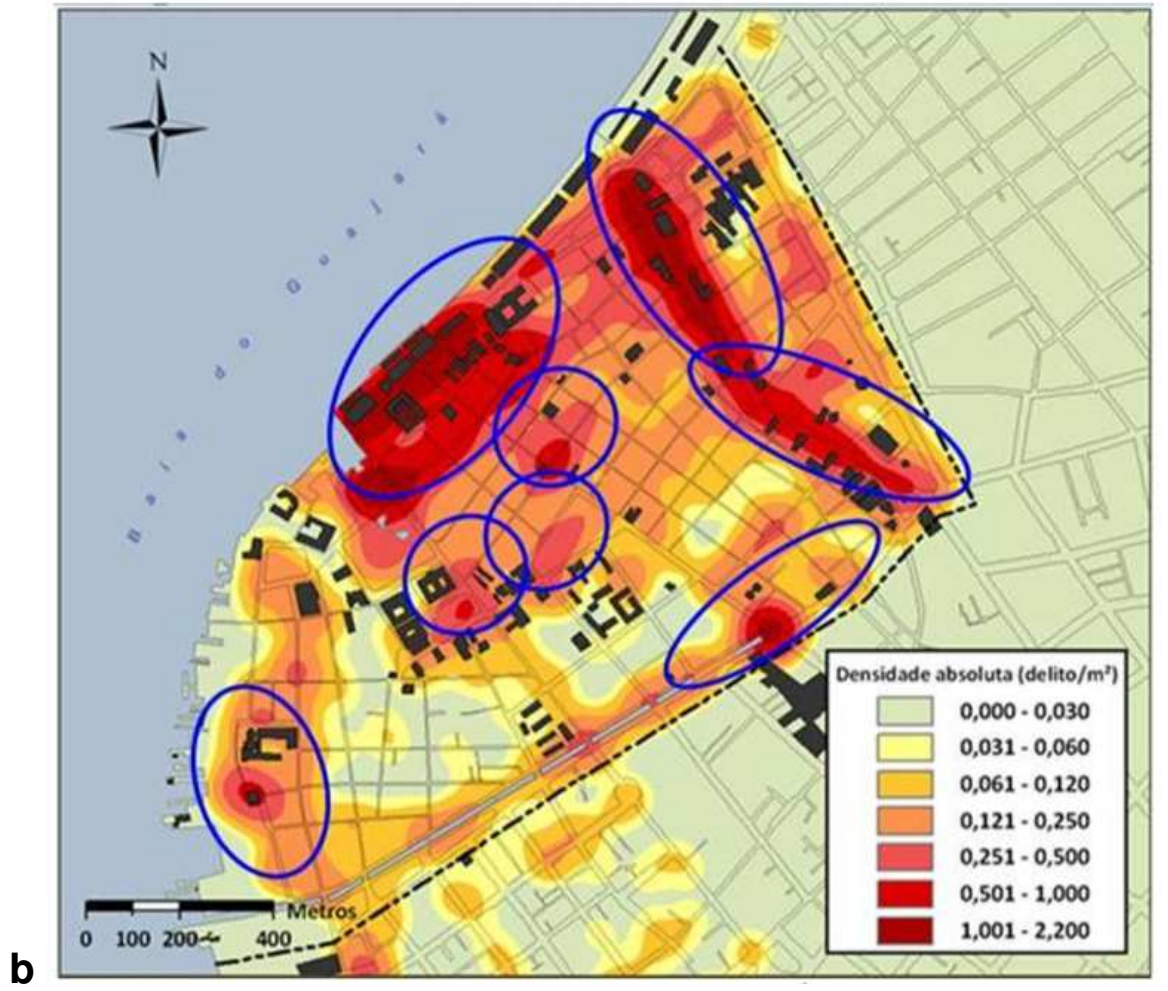

Fonte: Lobo e Guimarães (2013).

Essas três vias se caracterizam por serem relativamente largas (Figura 7a), ao contrário de muitas outras do centro comercial, que são bastante estreitas (Figura 7b). Este fato, em conjunto com a existência de vários hotspots próximos a praças, sugere que a concentração de ocorrências nesses locais está relacionada à maior facilidade de rotas de fuga para essas praças, pois a evasão do agressor é mais difícil nas ruas estreitas. Portanto, as possibilidades de rotas de fuga, algo enfatizado por diversos autores, parece ser algo de grande relevância para explicar a distribuição espacial dos furtos no CHB. 
Figura 7 - a) Av. Presidente Vargas, 2019 e b) Rua Santo Antônio, 2019

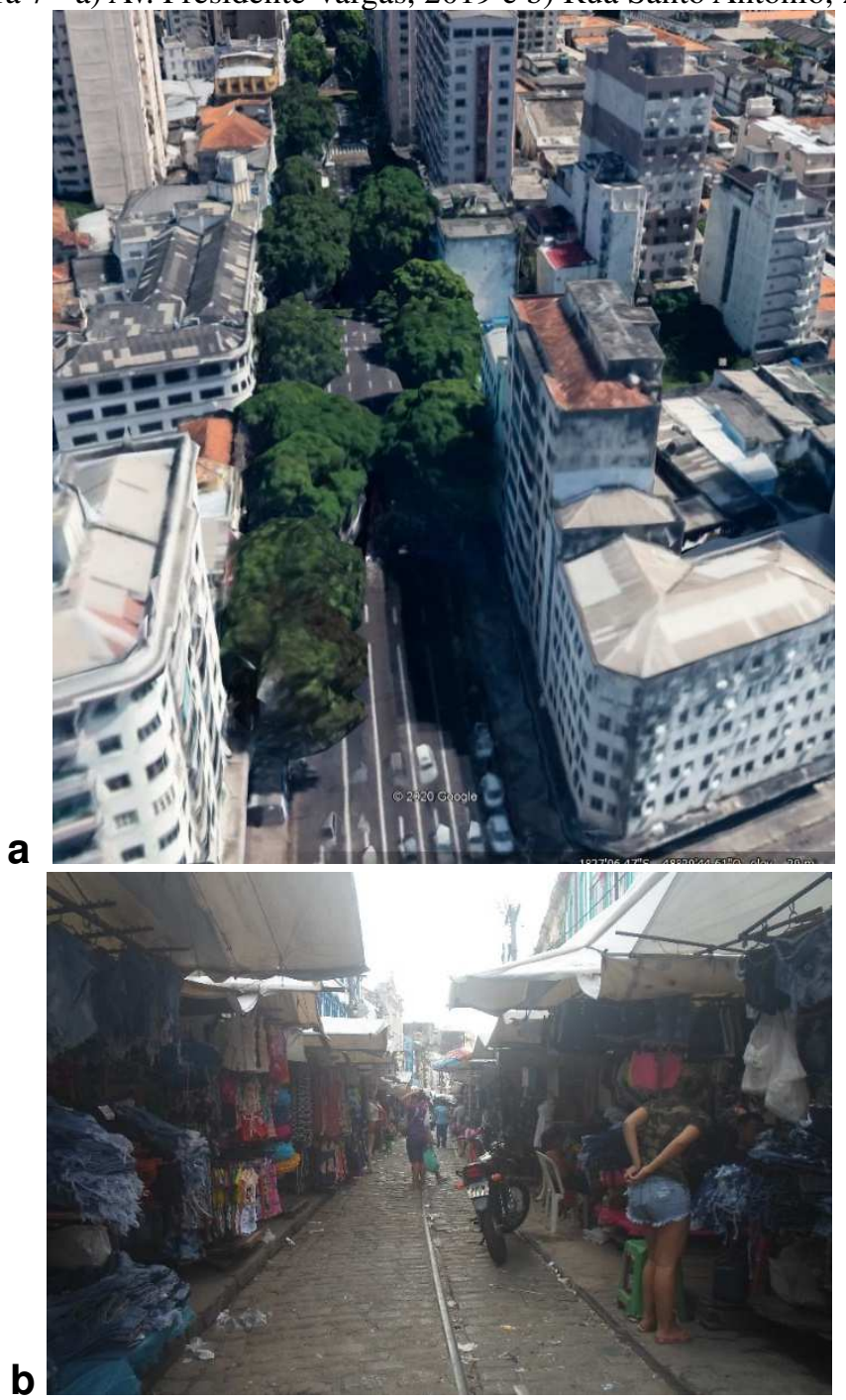

Fonte: Google Earth (a); Autores (b).

O padrão de distribuição espacial dos roubos não difere muito do padrão identificado para os furtos, seja em 2017 (Figura 8), seja no período jan. 2007 a out. 2008 (Figura 9). Notase que os locais onde estão as cores mais quentes do mapa de calor de roubos são muito próximos dos locais de concentração de furtos e a relação entre a localização dos hotspots em grandes vias e/ou proximidade de praças é ainda mais evidente. Também se deve lembrar que a motocicleta é um veículo que tem sido cada vez mais usado na prática de roubos, sendo que uma via larga facilita sobremaneira a fuga do agressor. 
Figura 8 - Distribuição espacial dos roubos no CHB, 2017

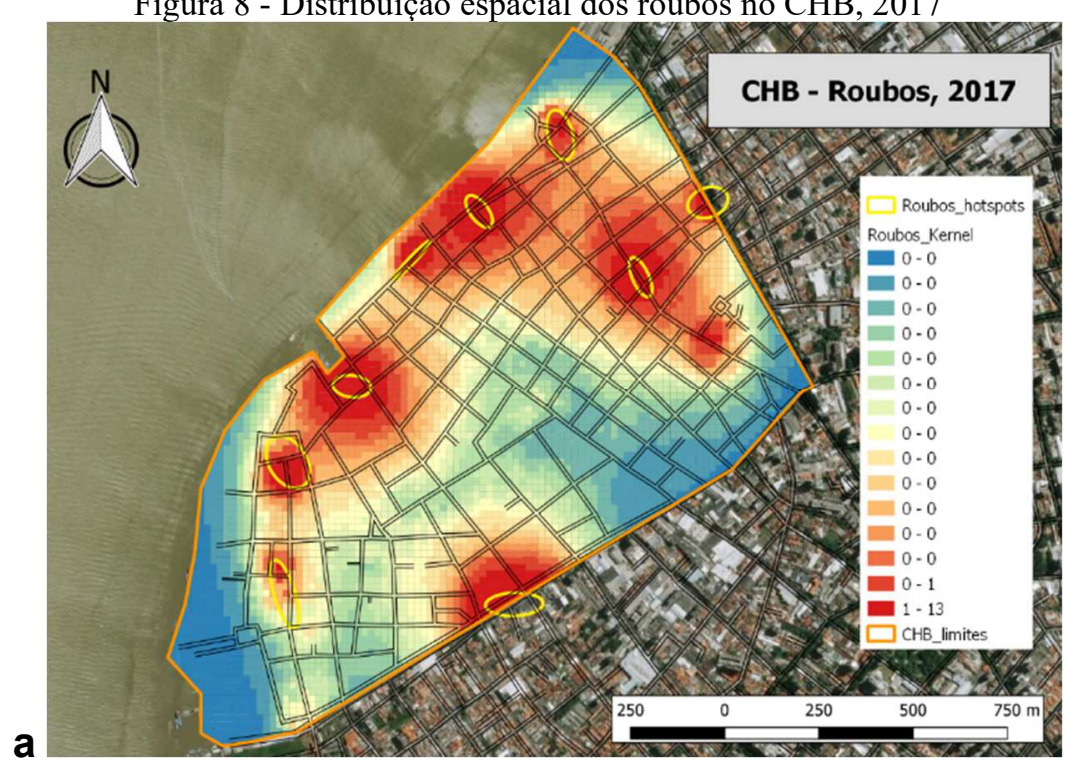

Fonte: Autores, com base em dados obtidos em Pará (2019).

Figura 9 - Distribuição espacial dos roubos no CHB, jan. 2007-out. 2008

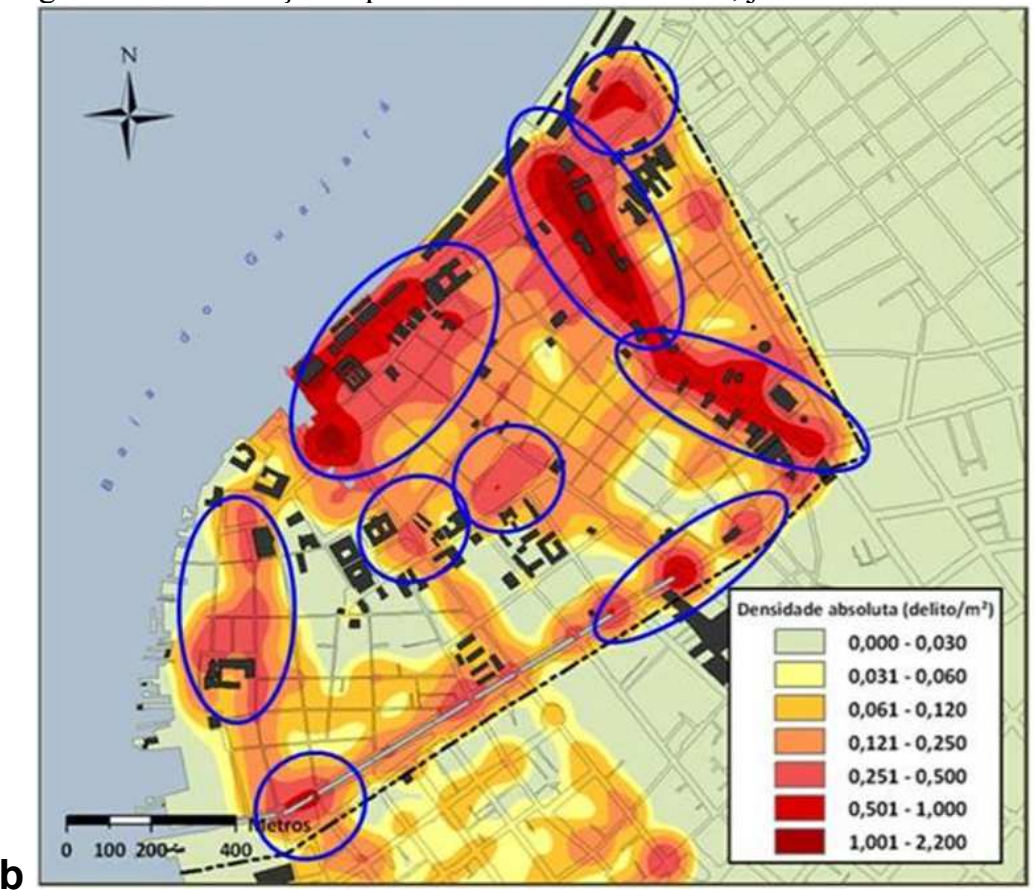

Fonte: Lobo e Guimarães (2013).

É importante considerar que furtos e roubos ocorrem em períodos distintos, como visto anteriormente. Enquanto para os furtos a incidência é maior durante o dia, para os roubos o período da noite é mais propício, tendo em vista que nesse horário o fluxo de pessoas é muito menor, os estabelecimentos estão fechando e as ruas contam somente com a iluminação pública. 
Outro aspecto relevante a considerar é o fato de que a presença de hotspots de criminalidade nas imediações das praças representa uma forte ameaça para que esses locais desempenhem o principal papel a que foram destinados: servir como locais de lazer e sociabilidade.

A degradação física do espaço construído do CHB deveria ser, em tese, outro aspecto a ser considerado na análise da ocorrência de crimes no CHB, especialmente no âmbito da teoria das janelas quebradas. Contudo, verifica-se que esse fator não é importante para explicar a distribuição espacial dos eventos criminais, pois enquanto a degradação do espaço físico acontece de forma generalizada do $\mathrm{CHB}$, os crimes contra o patrimônio se concentram nas áreas comerciais e ocorrem em escala bem menor nos locais predominantemente residenciais.

\section{CONSIDERAÇÕES FINAIS}

No presente artigo procurou-se investigar a quantidade e a forma como se dá a distribuição espacial de dois tipos de crimes contra o patrimônio no Centro Histórico de Belém - os furtos e os roubos - apoiado em teorias que relacionam o espaço construído com a criminalidade.

Observou-se que, no ano de 2017, o padrão dessa distribuição espacial se manteve praticamente o mesmo de dez anos antes: a grande maioria dos furtos e roubos ocorre nas áreas de maior concentração de usos comerciais localizadas em vias largas (corredores de transporte coletivo) e/ou próximas a praças. A diferença observada foi na quantidade desses delitos, que cresceu bastante em 2017 em relação ao período 2007-2008. É relevante destacar que a presença de hotspots nas imediações das praças do CHB constitui um fator bastante negativo para que esses espaços cumpram a função a que foram destinados: locais de lazer e sociabilidade.

A pesquisa verificou também que as teorias mencionadas no trabalho, sobre a relação entre organização do espaço urbano e criminalidade, são insuficientes para explicar a distribuição espacial dos delitos investigados. Torna-se necessário, então, desenvolver teorias que deem conta das peculiaridades dos centros históricos e comerciais de grandes cidades de países como o Brasil e outros do mundo não desenvolvido. De todo modo, alguns conceitos puderam ser aplicados à realidade do $\mathrm{CHB}$, como a concentração de alvos potenciais, a disponibilidade de rotas de fuga, obstáculos visuais em ruas muito cheias de pedestres que dificultam a percepção da prática de crimes e os macropadrões de deslocamentos cotidianos casa-trabalho. 
O maior conhecimento da relação entre a organização do espaço construído e a ocorrência de eventos criminais constitui uma contribuição importante para a implementação da segurança cidadã, especialmente em locais de permanência e circulação de muitas pessoas como o Centro Histórico de Belém. É nesse sentido que o presente trabalho pretendeu contribuir.

\section{REFERÊNCIAS}

BELÉM. Lei n. 7.709, de 18 de maio de 1994. Dispõe sobre a preservação e proteção do patrimônio histórico, artístico, ambiental e cultural do Município de Belém e dá outras providências. Diário Oficial [do Município]. Belém, 1994. Disponível em :

<http://www.belem.pa.gov.br/segep/download/coletanea/PDF/n_urban_p/patr_hist.pdf >. Aces so em : 12 jun. 2020.

COZENS, P.M., SAVILLE, G. ; HILLIER, D. Crime Prevention Through Environmental Design (CPTED): A review and modern bibliography. J. Prop. Manag, v. 23, n. 5, p. 328356, 2005. Disponível em:

<https://espace.curtin.edu.au/bitstream/handle/20.500.11937/19408/131503_CPTEDREVIEW-2005-

prepublication.pdf;jsessionid=76F4B4D6BDBD6578D65F75DF6164AF6B? sequence $=2>$. Acesso em: 30 out. 2019.

ENDLICH, A. M.; CARNEVALLI FERNANDES, P. H. Aumento da violência em pequenas cidades, sentimento de insegurança e controle social. Scr. Nova. Revista Electrónica de Geografía y Ciencias Sociales, v. 30, n. 493, 2014. Disponível em:

<https://revistes.ub.edu/index.php/ScriptaNova/article/view/15019/18372>. Acesso em:

HILLIER, Bill. Space is the machine: A configurational theory of architecture. London: Press Syndicate of the University of Cambridge, 2007. Disponível em:

<https://discovery.ucl.ac.uk/id/eprint/3881/1/SITM.pdf >. Acesso em: 30 jul. 2020.

INSTITUTO DE PESQUISA ECONÔMICA APLICADA; FORUM BRASILEIRO DE SEGURANÇA PÚBLICA. Atlas da Violência 2018. Disponível: em:

<http://www.ipea.gov.br/portal/images/stories/PDFs/relatorio_institucional/180604_atlas_da_ violencia_2018.pdf>. Acesso em 12 ago. 2019.

JACOBS, J. Morte e vida de grandes cidades. São Paulo: Martins Fontes, 2000.

LOBO, M. A. A.; GUIMARÃES, L. H. R. Distribuição espacial da criminalidade no Centro Histórico da cidade de Belém (Pará/Brasil). Scr. Nova. Revista Electrónica de Geografía y Ciencias Sociales. Barcelona: Universidad de Barcelona, 10 nov. 2013, v. 17, n. 456. Disponível em: <http://www.ub.es/geocrit/sn/sn-456.htm>. Acesso em: 25 set. 2019.

MANSO, B. P.; DIAS, C. N. A guerra: a ascensão do PCC e o mundo do crime no Brasil. São Paulo: Todavia, 2018.

NEWMAN, Oscar. Creating defensible space. Washington: US. Department of Housing and Urban Development, 1996. Disponível em:

<https://www.huduser.gov/publications/pdf/def.pdf>. Acesso em 10 ago. 2020. 
PARÁ. Secretaria de Segurança Pública. Polícia Civil. ACORR.xls, Belém, 24 de novembro de 2019. Arquivo (34.7 MB), Excel 365 for Windows.

SOARES, M.; SABOYA, R. T. Fatores espaciais da ocorrência criminal: modelo estruturador para a análise de evidências empíricas. Urbe. Revista Brasileira de Gestão Urbana, v. 11, 2019. Disponível em: <https://www.scielo.br/scielo.php?script=sci_arttext\&pid=S217533692019000100208>. Acesso em: 22 out. 2019.

SOUZA, M. J. N.; COMPANS, R. Espaços urbanos seguros: a temática da segurança no desenho da cidade. Rev. Bras. Estud. Urbanos Reg., São Paulo, v. 11, n. 1, p. 9-24, maio 2009. Disponível em: <https://rbeur.anpur.org.br/rbeur/article/view/207>. Acesso em: 22 maio 2019.

UNITED NATIONS OFFICE ON DRUGS AND CRIME. Global study on homicide 2019: extent, patterns, trends and criminal justice response. Vienna, 2019. Disponível em: <https://www.unodc.org/documents/data-and-analysis/gsh/Booklet2.pdf >. Acesso em: 3 ago. 2020.

WAISELFSZ, J. J. Mapa da violência 2015 - Homicídio de mulheres no Brasil. Brasília: Organização Pan-Americana da Saúde: Ministério das Mulheres, da Igualdade Racial e dos Direitos Humanos: Faculdade Latino-Americana de Ciências Sociais, 2015. Disponível em: $<$ http://www.onumulheres.org.br/wpcontent/uploads/2016/04/MapaViolencia_2015_mulheres.pdf>. Acesso em: 30 set. 2020.

WILSON, J. Q.; KELLING, G. L. Broken windows: The police and neighborhood safety. The Atlantic Online, v. 249, n. 3, p. 29-36, March 1982. Disponível em: <http://illinoisonline.org/krassa/ps410/Readings/Wilson\%20and\%20Kelling\%20Broken\%20Windows.pdf >. Acesso em: 12 jul. 2020. 